\title{
Hydrogen Smart-Grids: Smart Metering of Electricity from Hydrogen Fuel Cells
}

\author{
Gopalakrishnan Kumar ${ }^{1}$, Serhan Demirci ${ }^{2}$, Chiu-Yue Lin ${ }^{1,3^{*}}$ \\ ${ }^{1}$ Department of Environmental Engineering and Science, Feng Chia University, Taichung, Taiwan \\ ${ }^{2}$ Department of Business and Management, Feng Chia University, Taichung, Taiwan \\ ${ }^{3}$ Green Energy Development Center, Feng Chia University, Taichung, Taiwan \\ Email: ${ }^{*}$ cylin@fcu.edu.tw
}

Received March 5, 2013; revised April 6, 2013; accepted May 1, 2013

Copyright (C) 2013 Gopalakrishnan Kumar et al. This is an open access article distributed under the Creative Commons Attribution License, which permits unrestricted use, distribution, and reproduction in any medium, provided the original work is properly cited.

\begin{abstract}
In the last decade, increasing applications of information technology (IT) within power industry has become a significant reality. As distributed power networks are gaining importance and renewables are getting a bigger ratio within energy production, Smart Grid applications have become essential, especially due to the intermittent nature of renewable energy resources. Smart Grid is a sustainable energy system that measures, checks, and controls the generation, transmission, and consumption of electrical energy in grids on all voltage levels. Smart Grid experts are driving forward the development of effective communication and information technologies for the build-up of intelligent power supply networks. Examples of these are control systems for the realization of virtual power plants, intelligent consumer data acquisition systems, and smart distribution management systems. Fuel cell-based hydrogen electricity, in comparison to other renewable energy sources, is more stable and predictable. Yet hydrogen power and smart-grids have many application points, mainly as means of energy storage. This study claims that hydrogen energy and smart-grids could also engage through an appliance of IT managed metering of hydrogen power production. Smart metering and management of hydrogen fuel cells would enable advanced planning of short-to-mid-term power productions and thus foster use of hydrogen power within distributed networks, as local community or industrial applications.
\end{abstract}

Keywords: Smart Grids; Fuel Cell-Based Hydrogen Electricity; Virtual Power Plants

\section{Introduction}

In the last decade information communication technologies (ICT) advanced with an astonishing speed. Rapid expansion of ICT was a natural occurrence due to its crosscutting characteristic along different sectors. Information or in a simpler form data is a common commodity for every industry ranging in a wide variety, including energy, manufacturing, logistics and environment. Energy sector, in this sense, utilized information communication technology solutions to form intelligently distributed power networks, so called as Smart Grids.

The main objective of this study is to represent a model to build a "hydrogen smart grid" which could help to the community to make a connection between the smart grids with the hydrogen fuel cells. Thus provide the basic idea to be developed into a commercialized technology. The applications of the hydrogen smart grids could aid the community to attain the power without any interrup-

\footnotetext{
${ }^{*}$ Corresponding author.
}

tion from the hydrogen fuel cell-based power plant, which could use the hydrogen from various process such as thermo chemical and biological (dark and photo fermentation mainly) manners.

\section{Concept}

\subsection{What Is a Smart Grid?}

The Climate Group defines Smart Grid as a "set of software and hardware tools that enable generators to route power more efficiently, reducing the need for excess capacity and allowing two-way, real time information exchange with their customers for real time demand side management (DSM) [1].” Smart Grids improve efficiency of transmission and distribution lines by monitoring and communicating data across the power generation network. Smart Grid experts are driving forward the development of effective communication and information technologies for the build-up of intelligent power supply networks. Some application areas could be considered as 
control systems for the realization of virtual power plants, intelligent consumer data acquisition systems, and smart distribution management systems.

Smart Grid applications have become essential, especially due to the intermittent nature of renewable energy resources. Recently, renewable energy has been gaining a bigger ratio within whole power production spectrum. However, due to relatively unstable and unpredictable nature of common renewable sources (i.e. wind and solar), intelligently distributed power networks have also become a necessity. The load-balancing task has become much more challenging, forcing producers to adapt their output much more frequently, creating a need for intelligent management of power grid.

\subsection{Fuel Cell-Based Hydrogen Electricity (FCHE) and Smart Grid}

From grid management perspective, monitoring consumption/production rate has upmost importance to maintain load balancing. In a distributed power network, end nodes are capable of producing their own energy, using different sources like wind, solar or biomass. Typical renewable sources like wind and solar are intermittent and variable generators. Fuel cell-based hydrogen electricity (FCHE), on the other hand, is more predictable in nature. Rate of the reaction and volume of the hydrogen gas produced can easily be measured and metered. Smart metering of hydrogen output of a node (whether a resident, or a public building) in a Smart Grid could also be combined with smart metering of electricity utilization within that node. This would allow convenient estimation and planning of power utilization, including both consumption and production rates. Yet, most of the applications of hydrogen and Smart Grids have been limited to intelligent storage of the power produced as a means of hydrogen gas.

\subsection{Smart Metering}

Smart metering often refers to metering of electricity, however as the Smart Grid technologies evolve, metering of gas and water consumption have also been included within the definition. Main advantage of smart meters is that they are able to transmit real-time data in a bi-directional manner. Unlike conventional meters which measures total consumption value regardless of the time of consumption, smart meters provide an economical way of measuring real-time data, allowing price setting agencies to introduce different prices for consumption based on the time of day and the season.

For consumer either residential or industrial, smart metering offers a number of potential benefits including consumption estimation, planning and management, thus reducing costs and carbon emissions.
Around the globe there are a number of initiatives governed by different states. In 2008, the United Kingdom's Department of Energy and Climate Change (DECC) announced that energy suppliers would roll out gas and electricity smart meters to every home in Britain by the end of 2020. The United Kingdom rollout is considered to be the largest program ever undertaken-involving visits to more than 27 million homes to replace meters for both gas and electricity. As of January 2010 there were estimated to be in excess of 170,000 domestic smart meters installed [2].

In the United States, in July 20, 2006, California jurisdiction energy regulators approved a program to roll out conventional meters retrofit smart metering systems in 9 million residential customers in the Northern California territory. Similar initiatives have already been launched in Los Angeles, Houston, Dallas and San Antonio [3-5].

\subsection{Hydrogen Metering}

Although smart metering is rapidly expanding within electricity, gas and water grids; smart metering products and services available on the market are still lacking capability to integrate with a hydrogen fuel cell. This is due to the immature commercialization state of hydrogen energy, rather than technological deficits as the rate of hydrogen reaction and volume of the gas produced can easily be measured and metered with simple equipment already available. Smart metering devices could easily couple with hydrogen meters, enabling generation and transmission of hydrogen related data.

Smart metering of the hydrogen could provide a new era in the smart grids field. Smart Meter Manufacturers which were already not many are growing even smaller as the smaller independent companies are acquired by the larger more established giant MNCs. The Energy Efficiency and the Smart Grid industries will see a rapid growth as the demand grows for reducing global greenhouse emissions, increasing amounts of renewable energy integration into the grid and rising prices of fossil fuels. Unlike solar and wind industry, independent companies in the Smart Grid are not as large as they require relationships with utilities, a bigger portfolio of products and longer history to survive. Bigger companies like Cisco, Honeywell, and GE have mentioned the importance of Energy Efficiency and are going all out to achieve dominance. Smart Meter Manufacturers which traditionally had a presence in the water and gas metering and electricity would have a huge growth area in the hydrogen cells Smart Metering industry. With the power grid almost a 100 years old, newer smarter meters are needed as essential pieces of infrastructure to implement a smart grid along with the hydrogen cells where as the hydrogen era is going to evolve in the nearby future.

The big Smart Meter producing companies like Iton, 
Elster group, Landis + Gyr, Schieder Electric to be considered this concept of smart metering with hydrogen cells and promote the green business.

\subsection{Applications}

The integration of smart grids with the hydrogen fuel cells called hydrogen smart grids could have the possible applications such as:

1) Automatic control grids for the hydrogen plant;

2) Continuous power supply to the community from the hydrogen fuel cells without any interruption;

3) This hybrid system could be used in many places, such as big industries, remote areas etc.

\section{Discussion}

Hydrogen energy will evolve to higher level of commercialization in the following years, in line with ongoing scientific research on one hand, and business attempts on the other. Soon enough, there will be more products and services available for a better price, as the principle of economies of scale applies. Rather maiden nature of current state of hydrogen energy amplifies innovative motivation on all related fields, either scientific or commercial.

On the other hand, Smart Grids will diffuse more into conventional transmission and distribution networks as more initiatives are applied. Advancement in both technologies will push each other hand-in-hand. In this sense, commercialization of hydrogen energy coupled with smart metering would be accelerated. So the combined technologies of the hydrogen fuel cells with the smart grids could lead to useful power generation and their proper distribution, which is essentially needed nowadays. Thus a keen observation to hydrogen smart grids would bring a new era to the renewable energy technologies.

\section{Conclusion}

Smart Grid applications have become essential in current state of energy business, due to the increasing need for higher efficiency and accurate management. Data acquisition and transmission ability provided by information communication technologies were exploited to enable intelligent metering and monitoring of each node within power network, either as a consumer or producer. Smart Grids and hydrogen energy are primarily evolving technologies at hand, which would benefit from each other's advancements. Smart metering and management of hydrogen cells would foster commercialization of hydrogen power within smart grids. Hydrogen cells coupled with smart metering devices will be common implementation in residential or industrial areas.

\section{Acknowledgements}

The authors gratefully acknowledge the financial support by Taiwan’s Bureau of Energy (Grant No. 99-D0204-3), Taiwan's National Science Council (NSC-99-2221-E035-024-MY3, NSC-99-2221-E-035-025-MY3, NSC-992632-E-035-001-MY3), Feng Chia University (FCU-09G 27102) and APEC Research Center for Advanced Biohydrogen Technology.

\section{REFERENCES}

[1] Smart2020, "Enabling the Low Carbon Economy in the Information Age,” The Climate Group, 2008, p. 45.

[2] Energy Bill, "Amendment to the Energy Act 2008 Powers to Implement and Direct the Rollout of Smart Meters," The United Kingdom Department of Energy and Climate Change, 2010.

[3] News Release, "Pacific Gas and Electric Company’s SmartMeter ${ }^{\mathrm{TM}}$ Proposal Approved by California Public Utilities Commission,” Pacific Gas and Electric Company, 2006.

[4] Press Release, "Oncor Reaches Another Milestone in Smart Texas Advanced Meter Deployment,” ONCOR, 2009.

[5] Press Release, "Landis + Gyr Technology Enables Full Service Smart Grid Coverage,” Reuters, 2009 